Indian Journal of Clinical Biochemistry, 2003, 18 (2) 8-15

\title{
EFFECT OF HERBAL HYPOGLYCEMIC AGENTS ON OXIDATIVE STRESS AND ANTIOXIDANT STATUS IN DIABETIC RATS
}

\author{
Abbas Ali Mahdi ${ }^{*}$ Anu Chandra, Raj Kumar Singh, Sanjeev Shukla, L.C. Mishra ${ }^{\star \star}$ and Sohail Ahmad ${ }^{\star \star \star}$ \\ ${ }^{*}$ Department of Biochemistry, C.S.M. Medical University (upgraded King George's Medical College), Lucknow, \\ ${ }^{\star \star}$ Faculty of Life Sciences, C.S.J.M. University, Kanpur ${ }^{\star \star \star}$ Department of Pharmacology, State Govt. T.T. \\ College, Lucknow (U.P.), India
}

\begin{abstract}
:
In the present study the antioxidative potential of Momordica charantia, Azadirachta indica, Allium sativum and Ocimum sanctum was assessed in streptozotocin induced diabetic rats. Lipid peroxide levels were also measured in normal, diabetic and treated animals. Malondialdehyde (MDA) levels were significantly higher and antioxidant activity was found low in diabetic groups as compared to the control groups, and significant alteration in both the MDA levels and antioxidant activity was also observed when the above herbal hypoglycemic agents were given to diabetic rats. On the basis of our results we conclude that M.charantia, A.indica, A.sativum and O.sanctum are not only useful in controlling the lipid peroxide levels but are also helpful in further strengthening the antioxidant potential.
\end{abstract}

\section{KEY WORDS}

Free radicals, diabetes mellitus, antioxidants, herbal hypoglycemic agents.

\section{INTRODUCTION}

Once regarded as a single disease entity diabetes is now seen as a heterogenous group of diseases characterized by a state of chronic hyperglycemia, which causes a number of complications like cardiovascular, renal, neurological and ocular (1). Diabetes mellitus remains a major health problem and prevention of diabetes still lies in the realm of future and until then tens of millions will continue to suffer from this disease.

Oxidative stress is reported to be increased in patients with diabetes mellitus (2). Accumulating evidence suggests that oxidative cellular injury caused by free radicals contributes to the development of diabetes mellitus (3). Reactive oxygen species generated in the cells are scavenged by antioxidant enzymes (4). Moreover, diabetes also induces changes in the tissue content and activity of the antioxidant enzymes $(5,6)$.

Author for Correspondence :

Dr. Abbas Ali Mahdi

Department of Biochemistry,

C.S.M. Medical University

(upgraded King George's Medical College),

Lucknow-226003. (U.P.), India

e.mail: draamahdi@hotmail.com
Since the time of Charaka and Susruta many herbal medicines in different oral formulations have been recommended for Madhumeha and confident claims of cure are on record (7). It is well known that herbal plants like garlic (Allium sativum), Tulsi (Ocimum sanctum), Neem (Azadirachta indica) and Bittergourd (Momordica charantia) not only possess hypoglycemic activity but some of them are hypotensive, hepatoprotective and also blood purifier $(8,9)$.

In view of the above considerations the present study was designed to investigate the protective effect of $M$. charantia, $O$. sanctum, $A$. sativum and $A$. indica on plasma lipid peroxide levels and on anti-oxidant enzyme superoxide dismutase (SOD). Moreover, antioxidant molecules, uric acid and albumin content.was also measured in streptozotocin induced diabetic rats.

\section{MATERIALS AND METHODS}

A.indica leaves and O.sanctum leaves were collected from Medical University Campus, while A.sativum bulbs and M.charantia fruits were purchased from the local market of Lucknow. Alt the plants were identified taxonomically by 
Department of Pharmacology, State Government T.T. College, Lucknow.

\section{PREPARATION OF CRUDE EXTRACT}

M.charantia: Fresh fruits $(250 \mathrm{~g})$ were taken and seeds removed, the fleshy parts were cut into small pieces and macerated using a mortar and pestle. The products were squeezed through a muslin cloth and the liquid centrifuged at $5000 \mathrm{rpm}$ for 30 -minutes under refrigeration. The supernatant was used for study (10).

A.indica: Air dried plant leaves $(100 \mathrm{~g})$ were boiled in $200 \mathrm{ml}$ of distilled water for 10 -minutes. After cooling to room temperature, the supernatant was filtered to obtain the decoction ready for animal treatment (11).

A.sativum: Fresh garlic bulbs were cut into small pieces then about $25 \mathrm{ml}$ of distilled water per $100 \mathrm{~g}$ of garlic was added and crushed in a mixing machine. The resultant slurry was squeezed and filtered through a fine cloth and the filtrate quickly frozen (12).

O.sanctum: Air dried leaves powder was boiled in distilled water for 10-minutes. After cooling to room temperature, the supernatant was filtered to obtain the decoction ready for animal treatment (13).

\section{ANIMALS}

Male albino rats weighing $150-200 \mathrm{~g}$ were used in the present study. All rats were kept at room temperature of $20^{\circ} \mathrm{C}$ in the animal room of the Department of Biochemistry, C.S.M. Medical University, Lucknow. They were maintained on Hindustan Lever food pellets and water ad libitum.

48 rats, included for the study, were divided into 8 groups, each consisting of six animals. Out of 8 groups, seven were made diabetic with a single dose of streptozotocin $(65 \mathrm{mg} / \mathrm{kg} \mathrm{b.w}$.) by intraperitoneal route (14). Diabetes was confirmed by the determination of fasting blood glucose concentration on the third day post administration of streptozotocin.

Body weight and fasting blood glucose levels of all the rats were determined before the start of the experiment. Rats were divided into the following groups -
Group 1: Control given only saline $[10 \mathrm{ml} / \mathrm{kg} / \mathrm{once}$ a day, daily]

Group 2: Streptozotocin induced diabetic given in saline [10 $\mathrm{ml} / \mathrm{kg} /$ once a day, daily]

Group 3: Diabetic rats treated with $M$. charantia [10 ml/kg/ once in a day, daily] (10).

Group 4: Diabetic rats treated with A. indica [500 $\mathrm{mg} / \mathrm{kg} /$ once a day, daily] (15).

Group 5: Diabetic rats treated with $A$. sativum [10 $\mathrm{ml} / \mathrm{kg} /$ once a day, daily] (12).

Group 6: Diabetic rats treated with O. sanctum [250 $\mathrm{mg} / \mathrm{kg} /$ once a day, daily] (16).

Group 7: Diabetic rats treated with Insulin [5 units/ $\mathrm{kg} /$ once a day, daily] (17).

Group 8: Diabetic rats treated with Glibenclamide [500 mg/kg/ once a day, daily] (17).

After 30-days of treatment the body weight and fasting blood glucose of the animals were again determined. Blood was collected in heparinized vial and in plain vial for hemolysate preparation and for serum separation respectively.

\section{PREPARATION OF HEMOLYSATE}

Collected blood was centrifuged for 10-minutes at $3000 \mathrm{rpm}$. The plasma thus obtained was used for lipid peroxide estimation (18). Remaining packed RBCs were washed thrice with normal saline to remove the buffy coat. Hemolysis was performed by pipetting out $1 \mathrm{ml}$ of washed red blood suspension in ice cold distilled water. Erythrocyte ghosts were sedimented in a high speed refrigerated centrifuge at $12000 \mathrm{rpm}$ for 40 -minutes. The cell content was separated out carefully and used for superoxide dismutase estimation (19).

\section{SERUM SEPARATION}

The blood collected in plain vial was kept for some time. Serum from blood after clotting separated out and collected in clean centrifuge tube and again centrifuged for 5 -minutes at $3000 \mathrm{rpm}$. The serum thus obtained was used for albumin and uric acid estimations $(20,21)$. 


\section{RESULTS AND OBSERVATIONS}

In streptozotocin induced diabetic rats there was a significant $(p<0.001)$ increase in fasting blood glucose $(133.34 \%)$ and a comparative decrease $(p<0.001)$ in body weight and protein content. There was a slight increase in body weight and protein and a significant decrease in fasting blood glucose (Table 1) in diabetic rats treated with $M$. charantia $(45.03 \%)$, A. indica $(61.11 \%)$, A. sativum $(55.40 \%)$ and $O$. sanctum $(51.87 \%)$. These effects are quite similar to that obtained by insulin and glibenclamide.

Table 2 shows a statistically significant increase in lipid peroxide levels $(p<0.001)$ in streptozotocin induced diabetic rats with respect to normal controls and there was a significant decrease in lipid peroxide levels in diabetic rats treated with herbal preparations of M.charantia $(p<0.001)$, A.indica $(p<0.001)$, A.sativum ( $p<0.001)$, and 0. sanctum $(p<0.001)$. In contrast to this, activity of the enzyme superoxide dismutase was significantly decreased in diabetic rats as compared to that of normal control (Table 2). All the anti-diabetic agents including herbal preparations, insulin and glibenclamide used in the present study significantly elevated the activity of superoxide dismutase when compared with diabetic control, while $O$.sanctum showed no change in SOD activity (Table 2).

Another antioxidant, albumin was also found decreased in diabetic group as compared to normal control (Table 3). Following treatment with herbal preparations, except in case of A.indica, significantly increased levels of albumin were found. Insulin and glibenclamide also showed significant $(p<0.001)$ increase in albumin levels as compared to the control group (Table 3).

Following treatment with M.charantia, A.indica and A.sativum increment $(p<0.01)$ in the uric acid levels was observed, while O.sanctum, insulin and glibenclamide exhibited non significant changes (Table 3).

\section{DISCUSSION}

The results of the present study showed that extract of all the four plants namely $M$. charantia, $A$. indica, $A$. sativum and $O$. sanctum produces a marked decrease in blood glucose levels in normal as well as streptozotocin induced diabetic rats. The hypoglycemic effect of $M$. charantia, $A$. indica, $A$. sativum and $O$. sanctum extract increased gradually and was observed to be maximum at the end of the study period i.e. 4-weeks. Our findings are similar to those reported previously in case of $M$. charantia (14), A. indica (22), A. sativum (17) and O. sanctum (16).

The results of the present study demonstrated elevated plasma lipid peroxide levels in streptozotocin-induced diabetic rats along with a significant decrease in the anti-oxidant enzyme, superoxide dismutase activity. Moreover, we also found reduced levels of serum albumin and uric acid in diabetic rats. Eartier there have been many reports documenting elevated serum lipid peroxide levels and diminished antioxidant status in diabetic subjects $(23,24)$.

As diabetes and its complications are associated with free radical mediated cellular injury (25) herbal hypoglycemic agents were administered to diabetic rats to assess their anti-oxidant potential. Our results show that M.charantia, A.sativum, $O$.sanctum and $A$.indica not only have hypoglycemic activity but they also significantly reduce the plasma lipid peroxide levels in diabetic rats. Moreover, following treatment the activity of the anti-oxidant enzyme superoxide dismutase and serum albumin content was also found increased. However, the serum uric acid content was not found significantly altered. Uric acid is one of the most abundant chain breaking antioxidants present in human serum and its levels are largely determined by genetic factors, purine intake and renal function (26). Moreover, excess accumulation of urate in serum and tissues induce gouty pathology, and is by no means beneficial from the medical point of view (25).

SOD and albumin form the primary defense against reactive oxygen metabolites (27). Such metabolites have been implicated in the damage brought about by ionizing radiation, as well as in the effects of several cytostatic compounds (28). The decreased activity of antioxidant molecules along with elevated lipid peroxide levels in diabetic rats could probably be associated with oxidative stress and/or decreased antioxidant defense potential (29). The reversal in their content following treatment may be due to decreased oxidative load. Elevated SOD activity and albumin levels in insulin treated group may probably be due to the anabolic role of this proteinous hormone. The herbal hypoglycemic agents may also act by either directly scavenging the reactive oxygen metabolites, due to the 
presence of various antioxidant compounds (30), or by increasing the synthesis of anti-oxidant molecules.

Further studies are required not only to assess the status of other antioxidant enzymes and molecules in diabetics following treatment with herbal hypoglycemic agents, but also to evaluate the levels of metal ions such as copper, zinc, magnesium, manganese and selenium, as altered metabolism of these metals have been reported to occur in both IDDM and NIDDM (31).

\section{ACKNOWLEDGEMENT}

The authors are grateful to the Indian Council of Medical Research for providing financial assistance to one of us (AC) and also to Mr. Anuj Deep for typing work. 
Indian Journal of Clinical Biochemistry, 2003, 18 (2) 8-15

Table 1

The effect of herbal hypoglycemic agent on body weight, blood glucose and protein in normal and diabetic rats. Values are expressed as mean \pm S.E. $(n=6)$. Student's t-test.

\begin{tabular}{|c|c|c|c|c|}
\hline \multirow[t]{2}{*}{ Groups } & \multirow{2}{*}{$\begin{array}{c}\text { Change in body } \\
\text { weight }\end{array}$} & \multicolumn{2}{|c|}{ Fasting blood glucose (mg/dl) } & \multirow{2}{*}{$\begin{array}{l}\text { Protein value } \\
\text { (mg/ml) }\end{array}$} \\
\hline & & Pre-treated & Post-treated & \\
\hline Control & $+31.0 \pm 1.12$ & $80.83 \pm 2.75$ & $82.06 \pm 4.32$ & $59.48 \pm 2.86$ \\
\hline Diabetic control & $-16.5 \pm 2.2^{\star \star \star}$ & $188.60 \pm 2.91$ & $191 \pm 9.78^{\star \star}$ & $38.6 \pm 3.20^{\star \star \star}$ \\
\hline $\begin{array}{l}\text { Diabetic rats + } \\
\text { M. charantia }\end{array}$ & $+6.4 \pm 3.2^{\star}$ & $189.28 \pm 3.77$ & $105.25 \pm 6.58$ & $42.18 \pm 6.65^{\star}$ \\
\hline $\begin{array}{l}\text { Diabetic rats + } \\
\text { A. indica }\end{array}$ & $+4.5 \pm 1.05^{*}$ & $193.93 \pm 6.62$ & $74.45 \pm 2.48^{\star * \star *}$ & $40.66 \pm 7.52^{\star}$ \\
\hline $\begin{array}{l}\text { Diabetic rats + } \\
\text { A. sativum }\end{array}$ & $+5.3 \pm 1.4^{*}$ & $189.74 \pm 8.96$ & $85.39 \pm 17.1^{\star \star \star}$ & $40.88 \pm 6.52^{\star}$ \\
\hline $\begin{array}{l}\text { Diabetic rats + } \\
\text { O. sanctum }\end{array}$ & $+6.8 \pm 0.84^{\star}$ & $194.15 \pm 3.06$ & $92.15 \pm 24.0^{\star \star \star}$ & $47.73 \pm 5.93^{\star \star}$ \\
\hline Diabetic rats + Insulin & $+12.3 \pm 2.4^{* *}$ & $193.46 \pm 2.79$ & $77.42 \pm 4.03^{\star \star \star}$ & $43.68 \pm 7.51^{\star \star}$ \\
\hline $\begin{array}{l}\text { Diabetic rats + } \\
\text { Glibenclamide }\end{array}$ & $+0.2 \pm 1.35^{\star \star}$ & $194 \pm 2.77$ & $105.92 \pm 8.15^{* \star \star}$ & $42.65 \pm 2.30^{\star \star}$ \\
\hline
\end{tabular}

Group 2 is compared to group 1. Group 3, 4, 5, 6, 7 and 8 are compared to group 2. p-values: ${ }^{*} p<0.1,{ }^{\star \star} p<0.01,{ }^{\star \star *} p<0.001$ 
Indian Journal of Clinical Biochemistry, 2003, 18 (2) 8-15

Table 2

Effect of herbal hypoglycemic agents on the levels of lipid peroxide and superoxide dismutase. Values are expressed as mean $\pm S . E$. $(n=6)$. Student's t-test.

\begin{tabular}{|l|c|c|}
\hline Groups & MDA (nmol/ml) & SOD (U/mg protein) \\
\hline Normal control group & $2.98 \pm 0.373$ & $86.7 \pm 3.19$ \\
Diabetic control group & $8.79 \pm 0.564^{\star \star \star}$ & $59.5 \pm 2.43^{\star \star \star}$ \\
Diabetic rats + M. charantia & $3.39 \pm 0.126^{\star \star \star}$ & $80.0 \pm 4.03^{\star \star \star}$ \\
Diabetic rats + A. indica & $3.36 \pm 0.037^{\star \star \star}$ & $71.5 \pm 1.29^{\star \star \star}$ \\
Diabetic rats + A. sativum & $3.60 \pm 0.759^{\star \star \star}$ & $75.5 \pm 2.54^{\star \star \star}$ \\
Diabetic rats + O. sanctum & $2.97 \pm 0.090^{\star \star \star}$ & $62.2 \pm 2.64^{\star}$ \\
Diabetic rats + Insulin & $3.19 \pm 0.071^{\star \star \star}$ & $127.8 \pm 2.39^{\star \star \star}$ \\
Diabetic rats + Glibenclamide & $3.81 \pm 0.239^{\star \star \star}$ & $101.3 \pm 5.34^{\star \star \star}$ \\
\hline
\end{tabular}

${ }^{\star} p<0.1,{ }^{\star \star \star} p<0.001$ vs diabetic control group.

Table 3

Effect of herbal hypoglycemic agents on the levels of albumin and uric acid. Values are expressed as mean \pm S.E. $(n=6)$. Student's t-test.

\begin{tabular}{|l|c|c|}
\hline \multicolumn{1}{|c|}{ Groups } & Albumin $(\mathrm{g} / \mathrm{dl})$ & Uric acid $(\mathrm{mg} / \mathrm{dl})$ \\
\hline Normal control group & $2.72 \pm 0.169$ & $0.681 \pm 0.016$ \\
Diabetic control group & $2.11 \pm 0.1026$ & $0.568 \pm 0.055^{\star \star \star}$ \\
Diabetic rats + M. charantia & $2.65 \pm 0.1541^{\star \star \star}$ & $0.489 \pm 0.0081^{\star \star}$ \\
Diabetic rats + A. indica & $2.27 \pm 0.1360^{\star \star}$ & $0.663 \pm 0.0288^{\star \star *}$ \\
Diabetic rats + A. sativum & $2.62 \pm 0.4605^{\star \star \star}$ & $0.657 \pm 0.0330^{\star \star}$ \\
Diabetic rats + O. sanctum & $2.35 \pm 0.0496^{\star \star \star}$ & $0.581 \pm 0.0081^{\star}$ \\
Diabetic rats + Insulin & $2.72 \pm 0.1172^{\star \star \star}$ & $0.540 \pm 0.0638^{\star}$ \\
Diabetic rats + Glibenclamide & $2.65 \pm 0.0579^{\star \star \star}$ & $0.531 \pm 0.0066^{\star}$ \\
\hline
\end{tabular}

${ }^{\star} p<0.1,{ }^{\star \star} p<0.01$ and ${ }^{\star \star *} p<0.001$ vs diabetic control group. 


\section{REFERENCES}

1. WHO Expert Committees. In: WHO Technical report series of Diabetes mellitus 1985, 727.

2. Baynes, J.W. (1991) Role of oxidative stress in development of complications in diabetes. Diabetes 40, 405-412.

3. Bambolkar, S. and Sainani, G. S. (1995). Evaluation of oxidative stress in diabetics with or without vascular complications. J. Asso. Phys. India, 43, 10-12.

4. Genet, S., Kale, R. K. and Baquer, N.Z. (2002). Alterations in antioxidant enzymes and oxidative damage in experimental diabetic rat tissue; Effect of vanadate and fenugreek (Trigonella faenum graecum). Mol.Cell. Biochem. 236(1\&2), 7-12.

5. Wohaieb, S.A. and Godin, D.V. (1987) Alteration in free radical tissue defense mechanism in streptozotocin-induced diabetes in rat. Diabetes 36, 1014-1018.

6. Asayama, K., Kayashibe, H., Dobashi, K., Niitsu, T., Miyao, A. and Kato, K. (1989) Antioxidant enzyme status and lipid peroxidation in various tissues of diabetic and starved rats. Diabetes Res. 12, 85-91.

7. Aslam, M., Jafri, M.A., Kalim, Javed and Surendra Singh (1998) Plant drug with hypoglycemic activity Glimpses in plant Research, Vol XII : 271-299. Today and Tomorrow's Printers and Publishers, New Delhi-110005 (India).

8. Tiwari, A.K and Rao, M. (2002) Diabetes mellitus and multiple therapeutic approaches of phytochemicals: Present status and future prospects - Curr. Sci. 83, 30-38.

9. Grover, J.K., Yadav, S. and Vats, V. (2002). Medicinal plants of India with antidiabetic potential. J. Ethnopharmacol. 81, 81-100.

10. Karunanayake, H., Eric, Jeevathayaparan S., Tennekoon, H. Kamani (1990). Effect of Momordica charantia fruit juice on streptozotocin induced diabetes in rats. J. Ethnopharmacol. 30, 199-204.

11. Satyanarayan, K., Murty, D., Narayana Rai D., Krishna Rao Gopalakrishna, and Murty LB. (1978). A preliminary study on hypoglycemic and antihyperglycemic effects of Azardirachta indica Ind.J.Pharmacol. 10(3), 247-250.

12. Zacharis N.T., Sepastian K.L., Babu Philip and Augusti K.T. (1980). Hypoglycemic and hypolipidaemic effects of garlic in sucrose fed rabbits. Ind.J.Phys.Pharmacol. 24, 151-153.

13. Luthy, N. and Ortelio, M. (1964). A study of possible oral hypoglycemic factor in Albahaca morada Ocimum sanctum. Ohio J.Sci. 64(3), 222-224.

14. Shibib, B.A., Khan, L.A. and Rahman, R. (1993). Hypoglycemic activity of Coccinia indica and Momordica charantia in diabetic rats: depression of the hepatic glyconeogenic enzymes glucose 6-phosphatase and fructose 1,6 bisphosphatase and elevation of both liver and red cell count enzyme glucose6-phosphate dehydrogenase. Biochem.J. 292, 267-270.

15. Bopanna, K.N., Kannan, J., Sushma, G., Balaraman, R. and Rathod, S.P. (1997) Antidiabetic and anti-hyperlipaemic effects of neem seed kernel powder on alloxan diabetic rabbits. Ind.J.Pharmacol. 29, 162-167.

16. Dhar, M.L., Dhar, M.M., Dhawan, B.N., Mehrotra, B.N. and Ray, C. (1968). Screening of Indian plants for biological activity (part-I). Ind.J.Exp.Biol. 6, 232-247.

17. Sheela, C.G. and Augusti, K.T. (1996). Antidiabetic effects of onion and garlic sulfoxide amino acids in rats. Planta Medica. 61(4), 356-7.

18. Ohkawa, H., Ohishi, N. and Yagi, K. (1979) Assay for lipid peroxides in animal tissue by thio-barbituric acid reaction. Anal. Biochem. $95,357-358$.

19. McCord, J.M. and Fridovich, I. (1969) SOD enzyme function for erythrocuprein. J.Biol.Chem. 224, 6049-6055.

20. Rodkey, F.L. (1965) Direct spectrophotometric determination of albumin in human serum. Clin.Chem. 11, 478-487.

21. Eichhorn, E., Zalmanwaki, S., Rotenburg, E.A. and Fanis, B. (1961) Uric acid estimation in serum and urine. J.Clin.Pathol. 14, 450453. 
22. Khosla, P., Sangeeta, B., Singh, J., Seth, S. and Srivastava, R.K. (2000). A study of hypoglycemic effects of $A$. indica (Neem) in normal and alloxan diabetic rabbits. Indian $\mathrm{J}$. Physiol. Pharmacol. 44 (1), 69-74.

23. Sato, Y., Hotta, N., Sakamoto, N., Matsuoka, S., Ohishi, N. and Yagi, K. (1979) Lipid peroxide level in plasma of diabetic patients. Biochem. Med. 21, 102-107.

24. Oberley, L.W. (1988) Free radicals and diabetes. Free Radical Biol. Med. 5, 113-124.

25. Asayama, K., Uchida, N., Nakane, T., hayashibe, H., Dobashi, K., Amemiya, S., Kato, K. and Nakazawa, S. (1993) Antioxidants in the serum of children with insulin dependent diabetes mellitus. Free Radic.Biol.Med. 15, 597-602.

26. Situnayake, R.D., Thurnham, D.I., Kootathep, S., Chirico, S., Lunec, J., Davis, M. and McConkey, B. (1991) Chain breaking antioxidant status in rheumatoid arthritis: Clinical and laboratory correlates - Ann. Rheum. Dis. 50, 81-86.

27. Mahdi, A.A. (2002) Free radicals and other antioxidants. A text Book of Biochemistry by S.P. Singh, $3^{\text {rd }}$ edn. CBS Publishers and
Distributors, New Delhi. 545-555.

28. Marklund, S.L., Westman, N.G., Lundgren, E. and Ross, G. (1982) Copper and zinc containing superoxide dismutase, manganese containing superoxide dismutase, catalase and glutathione peroxidase in normal and neoplastic human cell lines and normal human tissues. Cancer Res. 42, 1955-1961.

29. Mahdi, A.A., Singh, R. and Singh, R.K. (1996) Role of reactive oxygen species and antioxidants in human disease: $A$ overview Persp. Biol. (Rai, V., Naik, M.L. Manoharacharry, C. Eds.) School of Life Sciences, World Laser Graphics, Raipur, 5570.

30. Gupta, S.K., Prakash, J. and Srivastava, S. (2002) Validation of traditional claim of Tulsi, Ocimum sanctum Linn. as a medicinal plant. Ind.J.Exp.Biol. 40, 765-773.

31. Walter, R.M., Jr., Uri-Hare, J.Y., Olin, K.L., Oster, M.H., Anawalt, B.D., Critchfield, J.W. and Keen, C.L. (1991) Copper, zinc, magnesium status and complications of diabetes mellitus. Diabetes Care. 14, 10501056. 